\title{
SALAS INFORMATIZADAS: LOCAL DE MÍDIAS TECNOLÓGICAS SUBUTILIZADO?
}

\author{
Marilia Pizzatto Bratti ${ }^{1}$
}

\section{RESUMO}

Este estudo, realizado durante o ano de 2011, teve por objetivo analisar, quantitativa e qualitativamente, a frequência de utilização da sala informatizada e construir um perfil do coordenador contratado para atuar na sala informatizada de vinte e quatro escolas da rede estadual de ensino da Gerência de Educação do município de Joinville (SC). Os resultados obtidos demonstraram um baixo índice de utilização da sala informatizada por parte da comunidade escolar e o baixo desempenho do coordenador desse espaço no que se refere ao cumprimento de sua função no contexto pedagógico. A baixa frequência de utilização da sala informatizada por parte dos professores e alunos sugere que ela constitui-se num espaço subutilizado com mídias tecnológicas também subutilizadas.

Palavras-chave: mídias, salas informatizadas, perfil do coordenador, mídia informática.

\section{COMPUTERIZED ROOMS: PLACE OF UNDERUTILIZED TECHNOLOGICAL MEDIA?}

\section{ABSTRACT}

This study, conducted during the year 2011, had the objective of analyzing quantitatively and qualitatively the frequency of use of computerized room and build a profile of the coordinator contracted to work in the computerized room of twenty four schools that belong to the state school system in the city of Joinville (SC). The results showed a low rate of use of computerized room by the school community and the poor performance of the coordinator of this space in terms of fulfilling their function in the educational context. The low frequency of use of computerized room by teachers and students suggests that it is up a underused space with technological media also underutilized.

Keywords: media, computerized rooms, coordinator profile, computer media.

\section{SALAS INFORMATIZADAS: LUGAR DE SUBUTILIZADO MEDIOS TECNOLÓGICOS?}

\section{RESUMEN}

Este estudio, llevado a cabo durante el año 2011, tuvo el objetivo de analizar cuantitativa y cualitativamente la frecuencia de uso de la sala informatizada y construir un perfil del coordinador contratado para trabajar en la sala informatizada di veinticuatro escuelas de la red de escuelas públicas de la ciudad de Joinville (SC). Los resultados mostraron una baja tasa de uso de la sala informatizada por la comunidad escolar y el bajo rendimiento del coordinador de este espacio en términos de cumplimiento de su función en el contexto educativo. La baja frecuencia de uso de la sala informatizada por profesores y alumnos sugiere que es un espacio infrautilizado con medios tecnológicos también subutilizados.

Palabras clave: medios de comunicación, salas informatizadas, perfil del coordenador.

\footnotetext{
${ }^{1}$ Universidade Presbiteriana Mackenzie. mariliapizzatto@hotmail.com
} 


\section{INTRODUÇÃO}

Do encontro entre a necessidade e a criatividade mediado pela ação humana surge a tecnologia e através da história é possível vislumbrar como o ser humano conseguiu atender e responder com criatividade as suas necessidades. Segundo Chaves (2004, p. 30) a tecnologia, pode ser compreendida (...) como qualquer artefato, método ou técnica criado pelo homem para tornar seu trabalho mais leve, sua locomoção e sua comunicação mais fáceis, ou simplesmente sua vida mais agradável e divertida.

As exigências da sociedade do início deste século XXI colocaram o conhecimento e o uso intensivo da informação e da tecnologia como características fundamentais da sociedade contemporânea. Possuir o conhecimento e despontar na produção das inovações tecnológicas tornou-se fundamental para as economias uma vez que este tipo de conhecimento se transformou num indicador de riqueza e poder das nações.

Mas em uma era volátil e de rápidas e constantes transformações o debate no cotidiano escolar acerca da importância das tecnologias é recente e encontra-se a reboque de políticas educacionais arcaicas. Para Moran (2009) as tecnologias, quando incorporadas ao cotidiano escolar são subutilizadas quando não suscitam novas práticas e baseiam-se em adaptações de normas e currículos.

E se considerarmos as mudanças no que se refere a ampliação e maior acessibilidade aos recursos tecnológicos, há que se reconhecer que grande parte da geração de alunos que ora frequenta a escola nasceu imersa em um ambiente mais rico em tecnologia, baseado nas mídias comuns e de grande acessibilidade como o rádio, a televisão e internet. Isto considerado, qual a postura da escola frente a essa nova geração?

É ponto comum que a escola não pode repetir as práticas arcaicas e ultrapassadas à nova geração de crianças que nasceu imersa numa cultura onde as inovações tecnológicas estão ao seu alcance. Isto porque elas possuem necessidades diferentes daquelas que nasciam há vinte ou trinta anos atrás. Mas como dar respostas diferentes a esses alunos e ao mesmo tempo ignorar as velhas fórmulas 
que trazem conforto e tranquilidade? Freire em diálogo com Papert (1995) aponta um caminho quando dialoga sobre a escola e a presença da tecnologia:

(...) a minha questão não é acabar com a escola, é mudá-la completamente, é radicalmente fazer que nasça dela um novo ser tão atual quanto a tecnologia. Eu continuo lutando no sentido de pôr a escola à altura do seu tempo. E por a escola à altura do seu tempo não é soterrá-la, mas refazê-la. (PAPERT \& FREIRE, 1995, n/p)

Assim sendo, a escola e sua equipe técnica-pedagógica deverão estar preparadas frente às exigências que ora se impõem investindo em programas de formação continuada para todos os profissionais que atuam no espaço escolar para que façam uso das tecnologias não apenas como ferramentas, mas recursos que possibilitem novas formas de aprender e ensinar.

Somente assim a sala informatizada, um espaço que coaduna as diversas tecnologias, pode atuar como estimuladora de novas formas de aprendizagem, já que se encontra localizada no interior da Unidade Escolar, construída e/ou adaptada para receber um conjunto de computadores, interligados entre si e conectados à internet. Este ambiente, além de oportunizar aos estudantes o acesso às tecnologias educacionais, facilita ao professor - no que se refere ao uso deste espaço - a manipulação de recursos como os softwares educacionais que irão atuar como facilitadores do processo de ensino e aprendizagem de seus alunos, além de poder ser utilizado como um espaço de suporte pedagógico ao professor para que este possa sair do lugar comum e ampliar seu cabedal de conhecimentos midiáticos.

Considerando então a importância da tecnologia no campo educacional implantou-se, com auxílio do Programa Nacional de Tecnologia Educacional (Prolnfo) do Governo Federal, salas informatizadas em cada uma das 62 Unidades Escolares distribuídas por oito municípios da área de abrangência da GERED (Gerência de Educação) Joinville que atenderiam, segundo levantamento de 2011, no ensino fundamental uma população de 24.557 alunos, no ensino médio 23.278 alunos e aproximadamente cerca de 2.549 docentes. 
Neste contexto, a Gerência de Educação de Joinville através do Núcleo de Tecnologia Educacional (NTE), desenvolveu a ação de acompanhar sistematicamente, através do registro de dados, o funcionamento e os projetos desenvolvidos pelas unidades escolares, bem como de oferecer suporte tecnológico adequado. Para a GERED e para o NTE a existência de um espaço na unidade escolar que abrigasse as diversas mídias e tecnologias deveria estimular os docentes e a comunidade escolar como um todo na construção de novas formas de aprendizagem, a melhorar a dinâmica de planejamento das aulas e a incentivar a criatividade. Entretanto, o que se observou é que na prática os espaços destinados à sala de tecnologia pouco alteraram a realidade escolar e muitas vezes estes espaços com profissional especificamente contratado para auxiliar o professor no planejamento e desenvolvimento de suas aulas permaneciam abertos com pouca ou nenhuma utilização. A baixa frequência de utilização deste espaço por parte dos docentes, aliado a subutilização das mídias foram os motivos que incentivaram o Núcleo de Tecnologia Educacional (NTE), no ano de 2011, a desenvolver dois instrumentos de diagnóstico e de controle que, preenchidos pelos coordenadores das salas informatizadas, deveriam retratar a realidade cotidiana do espaço bem como apontar possíveis caminhos para a superação das dificuldades encontradas.

Assim, a primeira ação proposta pelo NTE, no ano de 2011, foi construir um perfil do profissional candidato a coordenador da sala informatizada. A partir desse conhecimento prévio pretendia-se construir um diagnóstico a respeito da formação acadêmica e também desvelar a experiência na área de informática por parte do candidato a coordenador da sala informatizada. E, com o intuito de coordenar e monitorar o funcionamento das salas informatizadas, o NTE também desenvolveu no mesmo ano um outro instrumento de coleta de dados que, estendido a todas as unidades escolares estaduais da área de abrangência da Gerência de Educação de Joinville, tinha por objetivo acompanhar os projetos educacionais desenvolvidos e também orientar os profissionais contratados especificamente para atuarem nesse espaço.

Vale esclarecer que o ponto de partida e análise para a efetivação deste estudo foram os dados fornecidos mensalmente pelas unidades escolares e enviados ao NTE no ano de 2011 referentes ao funcionamento das salas informatizadas, bem 
como os dados de uma ficha cadastral utilizada com o intuito de construir um perfil do profissional coordenador destas salas.

Como tema central deste estudo, tem-se a investigação a respeito das salas informatizadas (explicitando o emprego da mídia informática) da rede estadual de ensino localizada no município de Joinville com o intuito de analisar a frequência de utilização do espaço da sala informatizada nas unidades escolares da rede estadual de ensino do município de Joinville bem como tratar a mídia informática como um importante diferencial na construção da aprendizagem significativa. O presente estudo caracterizou-se como uma pesquisa quantitativa de natureza survey e teve por objetivos: a) quantificar e analisar a frequência de utilização do espaço da sala informatizada nas unidades escolares da rede estadual de ensino do município de Joinville; b) identificar, analisar e refletir acerca das principais dificuldades encontradas durante a utilização do espaço da sala informatizada.

Convém destacar que a intenção primeira da pesquisa era trabalhar a partir dos dados mensais das 42 unidades escolares da rede estadual de ensino situadas no município de Joinville (SC), durante o ano de 2011. Entretanto, percebeu-se que o compromisso com o levantamento de dados proposto pelo NTE não foi abarcado por um número significativo de escolas e seus respectivos gestores que se deram o direito de ignorar a solicitação feita pelo órgão maior. A inobservância desta solicitação traduziu-se em formulários preenchidos inadequadamente, com dados incompletos, falta de assinaturas, e informações indecifráveis. Logo, de um total de 42 unidades escolares estaduais, apenas 24 escolas comprometeram-se, ainda que parcialmente, em enviar os dados solicitados mensalmente. Os dados considerados aqui são das UEs que encaminharam seus dados por pelo menos cinco meses no ano de 2011.

\section{DECIFRANDO OS DADOS COLETADOS}

Para uma melhor compreensão dos dados coletados dividiu-se as informações em dois focos de análise denominados: $1^{\circ}$. 'Coordenador da Sala Informatizada: que profissional é este?' que apresenta o perfil do coordenador da sala informatizada no ano de $2011 ; 2^{\circ}$. 'Sala Informatizada: que espaço é este?' descreve o percentual de frequência de utilização deste espaço. 
$1^{\circ}$. 'Coordenador da Sala Informatizada: que profissional é este?

O profissional considerado adequado pela Secretaria de Educação do Estado de Santa Catarina, segundo o Edital no 18 de 2010, para atuar no espaço das salas informatizadas no ano de 2011 deveriam possuir, para fins de contratação e remuneração, os seguintes pré-requisitos:

\section{Candidato Habilitado \\ (com remuneração adequada a sua formação específica mais curso de Licenciatura e/ou Complementação Pedagógica)}

- Diploma e Histórico Escolar de Conclusão de Curso Superior em

Informática, Ciência da Computação, Sistemas de Informação, Redes de

Computadores, Manutenção de Computadores ou

- Tecnólogo em Informática

- Curso Emergencial de Licenciatura Plena de Formação de Professores ou Complementação Pedagógica.

\section{Candidato Não Habilitado}

(com menor remuneração devido a ausência de formação específica para atuar na área e sem curso de Licenciatura e/ou Complementação Pedagógica)

- Diploma e Histórico Escolar de Conclusão de Curso Superior em

Informática, Ciência da Computação, Sistemas de Informação, Redes de

Computadores, Manutenção de Computadores, Engenharia de Computação ou

- Tecnólogo em Informática, ou

- Diploma e Histórico Escolar de Conclusão de Curso de Ensino Médio na área de Informática, ou

- Certidão de frequência a partir da $1^{a}$ fase em Curso de Graduação em Informática, ou Ciência da Computação, ou Sistemas de Informação, ou Redes de Computadores, ou Manutenção de Computadores, ou Engenharia de Computação, ou

- Tecnólogo em Informática, ou

- Diploma e Histórico Escolar de Conclusão de Curso Superior com comprovante de curso na área de informática com no mínimo 60 (sessenta) horas, ou

- Diploma ou Certificado de Conclusão de Curso de Ensino Médio na área de Informática ou,

- Diploma ou Certificado de Conclusão de Curso de Ensino Médio mais comprovante de curso na área de informática com no mínimo 60 (sessenta) horas.

Fonte: http://www.sed.sc.gov.br/secretaria/documentos/doc_download/1309-edital-act-no18\%20EDITAL\%20№\%20\%20\%2018/2010/SED

Levando-se em consideração os pré-requisitos estabelecidos pela Secretaria de Estado da Educação (SED) de Santa Catarina ao final do ano de 2010 e a formação apresentada pelos profissionais contratados para atuar na sala 
informatizada no ano de 2011 foi possível concluir que os profissionais contratados possuíam formação educacional compatível com aquelas exigidas no referido edital.

Seria então de se esperar que um profissional que se inscrevesse para atuar como coordenador de uma sala informatizada, ainda que em caráter temporário, com formação compatível com aquelas estabelecidas no edital, atendesse e cumprisse com as atribuições do coordenador da sala informatizada previstas pela Gerência de Tecnologias Educacionais e Infraestrutura do Estado de Santa Catarina. Entretanto o que se concluiu, a partir da análise dos dados, coletados foi que se as salas informatizadas tiveram um baixo índice de utilização, logo, ou esse profissional permaneceu no espaço escolar sem executar as funções a que foi contratado ou passou a desenvolver outras atividades não condizentes a sua função no espaço escolar deixando a sala informatizada em segundo plano.

Outro fator que suscita reflexão diz respeito à inexistência, no ano de 2011, de candidatos considerados habilitados e, na falta de profissionais habilitados para atuar nesse espaço a Gerência de Educação obrigou-se a efetuar a contratação de profissionais que se adequassem a categoria de profissionais não-habilitados. Assim, apropriando-se dessa realidade e longe de afirmar que a ausência de profissionais com formação específica seja responsável pela baixa frequência de utilização das salas informatizadas, observou-se que os candidatos contratados possuíam formação educacional diversificada em várias áreas e uma formação específica limitada no que se refere à informática educacional.

Os profissionais contratados afirmaram possuir um conhecimento intermediário acerca dos editores de texto, o que nos alerta para a constatação de que conhecer, ainda que em nível intermediário os editores de texto, não significa que esses coordenadores terão uma prática na sala informatizada que supere o instrucionismo. Também se observa que possuir esse tipo de conhecimento é fundamental para um coordenador de sala informatizada. Entretanto, segundo Valente \& Almeida (1997), o que se espera de uma sala informatizada equipada com computadores é que esse espaço e que essas mídias sejam utilizadas para a promoção de mudanças pedagógicas. Destacam também os autores que possuir conhecimentos específicos acerca da informática educacional não garante que os 
responsáveis pelas salas informatizadas sejam capazes de aplicar esse conhecimento.

No processo pedagógico mediado pela tecnologia compete então ao coordenador da sala informatizada auxiliar o professor no processo de gestão da aprendizagem, ou seja, trabalhar no sentido de que a tecnologia seja incorporada ao cotidiano pedagógico de uma forma crítica, que supere a simples manipulação da máquina e de seus programas.

Utilizar a tecnologia em favor da promoção de uma educação de qualidade requer que que os órgãos competentes pela mesma ampliem sua compreensão acerca das salas informatizadas, sua função no âmbito escolar bem como acerca da contratação de seus profissionais. A Secretaria de Estado da Educação, responsável por elaborar o edital de seleção e contratação destes profissionais no afã de implementar tais salas, seja por interesses eleitoreiros ou então como forma de justificar a aplicação de recursos recebidos e não deixar a sala informatizada desassistida em nenhum momento vincula a contratação do profissional, ainda que em caráter temporário, a participação e frequência regular deste em programas de formação continuada ficando portanto a formação, a critério de cada coordenador.

O Núcleo de Tecnologia Educacional (NTE), apesar de ter a incumbência de trabalhar diretamente com esse profissional, não possui autonomia para interferir, alterar e / ou suspender a contratação desses profissionais. Compete, portanto ao NTE acompanhar o cotidiano de funcionamento das salas informatizadas e orientar esses coordenadores quanto as suas atribuições específicas. Vale ressaltar que se o profissional contratado para atuar na sala informatizada ignorar e / ou descumprir com suas atribuições no exercício de suas atividades, o NTE não possui autonomia e poder de pedir o desligamento desse profissional. Também, se o gestor da unidade escolar comprovar através de relatórios, testemunhas e depoimentos que esse coordenador não desempenhou a contento suas atividades, o processo para pedir o desligamento desse profissional é burocrático e moroso. Ou seja, uma vez contratado o coordenador da sala informatizada, há muito pouco o que se fazer, por parte do Núcleo de Tecnologia Educacional e da Unidade Escolar caso este profissional não tenha a capacidade, decida ignorar suas atribuições e/ou desenvolva ações em desacordo 
com o projeto político pedagógico da unidade escolar e com a proposta curricular do Estado de Santa Catarina.

No entanto, se espera minimamente de uma Secretaria de Educação que se diz preocupada com a qualidade que coloque em prática uma política educacional que encare as necessidades pedagógicas escolares com seriedade ao invés de estabelecer em editais maquiados subterfúgios temporários para sanar a falta de profissionais habilitados para atuar nas salas informatizadas.

$2^{\circ}$. 'Sala Informatizada: que espaço é este?

As unidades escolares no ano de 2011 pouco utilizaram a sala informatizada suscitando o questionamento acerca da necessidade da sua existência no espaço escolar assim como da contratação de um profissional específico para atuar como coordenador destas salas. Em média, considerando os dados de fevereiro a novembro de 2011, do total de aulas disponíveis - a base é 14 aulas por dia letivo quando a unidade escolar funciona em três turnos e 10 aulas quando em dois turnos - as salas informatizadas foram utilizadas em somente $23,3 \%$ delas. Trazendo para a realidade escolar, isto significa que a sala foi utilizada apenas um dia por semana. O mês com a melhor taxa de utilização foi julho, com 30,5\% das aulas disponíveis utilizadas e o pior foi fevereiro, com somente $14,7 \%$ ou como mostra a figura abaixo: 


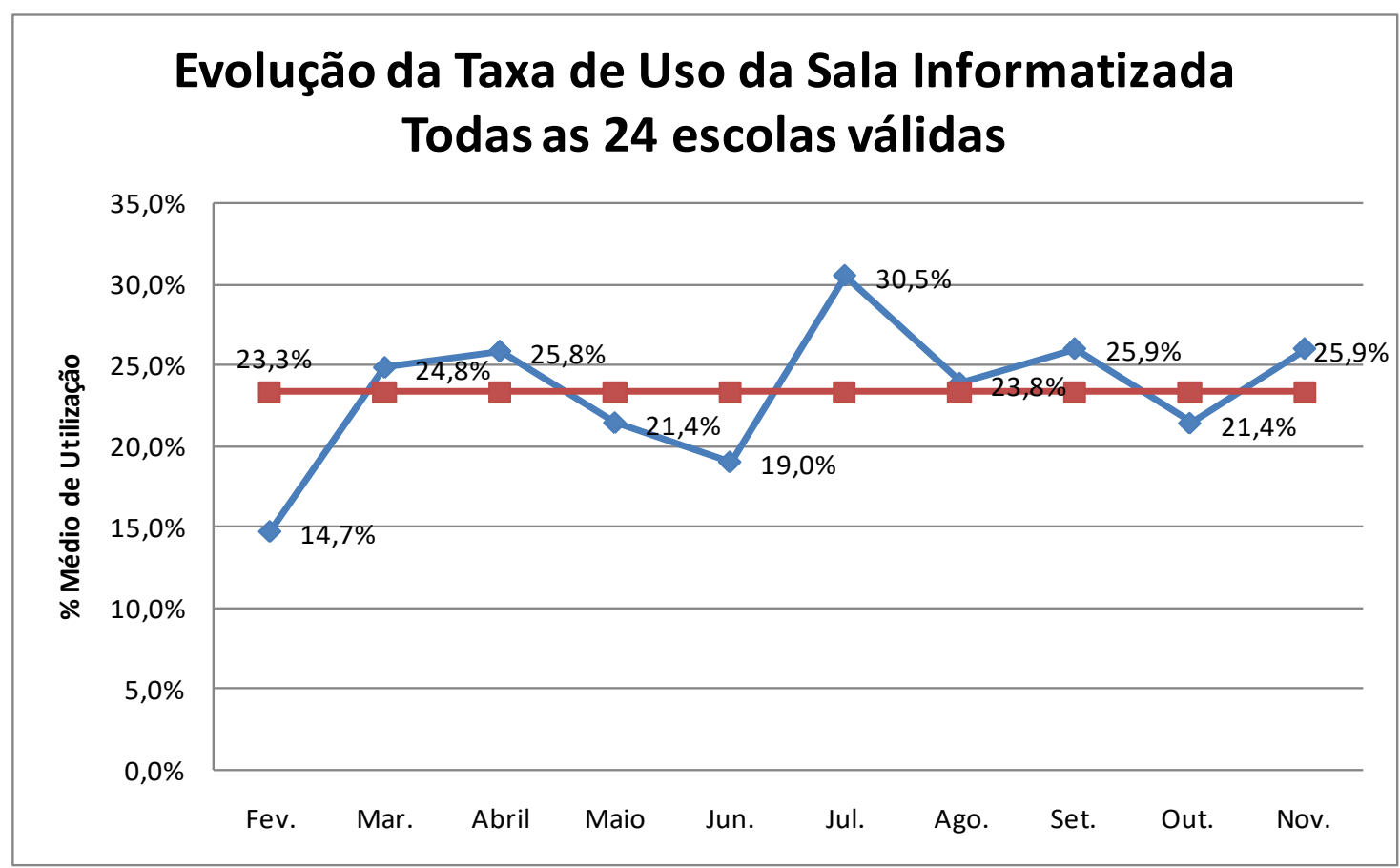

É fato que as unidades escolares necessitam de vários investimentos, seja no que se refere a ampliação do espaço físico, seja na contratação de profissionais capacitados para auxiliar no processo pedagógico e que a baixa qualidade da maior parte do parque de máquinas (computadores) disponíveis na unidade escolar constitui-se num fator significativo a se considerar. Entretanto, este estudo demonstra que a existência de um parque de máquinas atualizado também não se constitui em garantia para que a frequência de utilização da sala informatizada aumente no contexto escolar. A esse respeito concorda-se com Costa $(2004$, p. 3) quando afirma: "Assim, talvez mais do que possuir o 'último grito' tecnológico, a questão principal seja saber como tirar partido e rentabilizar qualquer tecnologia, mesmo que 'ultrapassada"'. Desta forma, não se trata de avaliar, de forma entusiasta, os atributos que uma nova tecnologia propiciará ao ambiente escolar e sim de considerar as contribuições que essa mídia proporcionará ao processo de ensino e aprendizagem. E também considerar, sobretudo, que as tecnologias são derivadas da apropriação humana, e dessa apropriação, que deve ser de natureza consciente e crítica por parte dos professores e coordenadores da sala informatizada, depende o seu impacto no processo de aprendizagem. 
Assim, mais do que equipar as escolas com equipamentos melhores e mais atualizados entende-se que faz-se necessário uma mudança de paradigma no que se refere a utilização da sala informatizada no espaço escolar e considerar até que ponto a escola tem se valido da mídia informática e das tecnologias como um todo para instrumentalizar os estudantes para uma aprendizagem mais crítica de estímulo a autonomia. Cabe à equipe escolar compreender a utilização da mídia informática não apenas como ferramenta, mas como tecnologia que estimula a criatividade e possibilita novas formas de aprendizagem.

A questão da baixa frequência de utilização das salas informatizadas não pode ser compreendida a partir de um paradigma cartesiano, limitado e descontextualizado da realidade. A superação de um paradigma que reduz e simplifica a realidade proporciona a compreensão de que a baixa frequência de utilização da sala informatizada não se encontra vinculada somente à defasagem do parque de máquinas das unidades escolares. Assim era de se esperar que a taxa de utilização fosse pior nas unidades escolares com o parque de máquinas mais deteriorado, mas cruzando as informações das duas análises: situação do parque de máquinas e taxa de uso das salas informatizadas, não é possível afirmar que a segunda tem relação direta com a primeira. Entre as escolas com maior taxa de utilização existem escolas com computadores precários bem como escolas com parque de máquinas bom entre as escolas com menor taxa de utilização.

\section{CONSIDERAÇÕES FINAIS}

As tecnologias estão a serviço dos seres humanos e estimular um pensamento sistêmico que incentive a curiosidade e a autonomia dos estudantes de forma que estes consigam apropriar-se da tecnologia criticamente e transformar a informação em um conhecimento comprometido com a construção de bases sociais mais éticas e solidárias representa o maior desafio da escola do século XXI.

E para dar respostas condizentes ao desafio proposto neste século equipou-se as unidades escolares com salas informatizadas. A partir da utilização destas objetivava-se (re)significar o processo de ensino e aprendizagem de forma a superar o instrucionismo e caminhar para a utilização da mídia informática como uma 
tecnologia capaz de fazer parte da vida dos docentes e dos alunos e auxiliá-los a resolverem seus problemas.

Entretanto, a partir da análise dos dados coletados em 24 das 42 unidades escolares da rede estadual de ensino que compunham a Gerência de Educação (GERED) e se localizam no município de Joinville no ano de 2011 pode-se afirmar que a sala informatizada se transformou num ambiente subutilizado. Com uma média anual de utilização de $23,3 \%$ a sala informatizada permaneceu mais tempo fechada ou em desuso do que sendo ocupada para atividades pedagógicas.

Outra questão investigada neste estudo diz respeito ao perfil do profissional contratado para atuar como coordenador da sala informatizada. Os dados coletados demonstraram que no ano de 2011 nenhum dos candidatos inscritos foi considerado habilitado para assumir a coordenação deste espaço e que os profissionais contratados atendiam minimamente aos requisitos do edital da Secretaria de Educação. As regulamentações previstas neste edital deixaram em aberto e/ou a critério de cada profissional a participação e frequência em cursos de formação continuada na área da informática educacional. Acredita-se que esta desregulamentação acabe estimulando, por parte destes coordenadores, certo descomprometimento com o aperfeiçoamento de sua prática bem como com a execução de um trabalho alinhado com o projeto político pedagógico da unidade escolar e com a proposta curricular do Estado de Santa Catarina.

O Núcleo de Tecnologia Educacional (NTE) que tem por função planejar, coordenar e avaliar o funcionamento das salas informatizadas no que se refere a sua utilização pedagógica no espaço escolar, possui autonomia limitada no que se refere a contratação dos coordenadores que atuarão na sala informatizada além de funcionar com um número reduzido de funcionários, sem possibilidades de deslocamento próprio, incapazes de atender a toda demanda de trabalho das salas informatizadas e de seus coordenadores. E, ainda que existam dificuldades de locomoção para as unidades escolares é crucial estabelecer uma agenda de acompanhamento in loco destes espaços.

A Secretaria de Estado da Educação, na ânsia de colocar profissionais em sala de aula, deixa para segundo plano a preocupação com a qualidade dos trabalhos realizados por estes coordenadores. Acredita-se que o mais coerente a fazer neste 
caso diz respeito a vincular a contratação do profissional à participação e frequência deste em cursos que estimulem a utilização da mídia informática contextualizada com o espaço escolar e que supere o uso mecanicista desta tecnologia. Neste sentido, caberia ao Núcleo de Tecnologia Educacional promover constantemente ao longo do ano letivo momentos de discussão, reflexão e formação continuada a estes coordenadores bem como propiciar local de debate acerca das possibilidades de utilização da mídia informática no contexto escolar.

No entanto não se pode perder de vista que a presença de um coordenador de sala informatizada com formação adequada para atuar neste espaço não se constitui em garantia de ações de qualidade. Acredita-se que quanto mais o coordenador da sala informatizada estiver ambientado com o universo escolar em que estiver atuando e existirem planejamentos frequentes, diálogo e reflexão acerca da real função da tecnologia no espaço escolar entre professores, equipe diretiva, coordenadores e estudantes mais uso e utilidade terá a sala informatizada.

A equipe gestora das unidades escolares também possui sua parte de responsabilidade quanto ao parco funcionamento das salas informatizadas no ano de 2011. Os formulários de coleta de dados que demonstravam a utilização deste espaço foram avalizados pelos gestores através de suas assinaturas. Assume-se que os gestores escolares possuam competência técnica para ocuparem a função, então ou os gestores consideraram tais documentos de forma burocrática sem efetuar uma leitura crítica acerca dos dados ali informados ou preferiram ignorar tais dados demonstrando despreocupação com a qualidade do processo de ensino aprendizagem desenvolvido na sala informatizada existente na sua unidade escolar e também com os gastos públicos advindos da contratação de um profissional que não está sendo utilizado.

Mais do que procurar responsáveis para a questão da baixa utilização das salas informatizadas é fundamental que se destaque que somente uma ação coordenada por parte da Secretaria e Gerência da Educação, do Núcleo de Tecnologia Educacional, das Unidades Escolares e dos Coordenadores das salas informatizadas ainda não garantiriam que a sala informatizada atingisse um objetivo pedagógico mais elevado. 
Nesta ação coordenada os professores também devem ser inseridos, pois o que se quer é que, a partir da utilização das tecnologias digitais de informação e comunicação e a convergência das diversas mídias, seja oportunizado ao aluno uma aprendizagem que estimule a curiosidade, uma aprendizagem compartilhada e a possibilidade de construir novos conhecimentos a partir de uma nova leitura de mundo. Para que isso aconteça é fundamental que todos participem com qualidade, responsabilidade, comprometimento e sobretudo com conhecimento crítico científico, cada um em sua esfera de atuação.

\section{REFERÊNCIAS}

COSTA, F. A. Razões para o fraco uso dos computadores na escola. Revista Diálogo Educacional, vol.4, n.12, maio-ago. 2004, p. 1-13, Disponível em < https://www.academia.edu/744074/Raz\%C3\%B5es_para_o_fraco_uso_dos_comput adores_na_Escola >. Acesso em 23 jun. 2012.

CHAVES, E. O. C. Tecnologia na educação. Rev. de Educ - PUC - Campinas, v.3, n.7, p. 29-43, nov. 1999. Disponível em < periodicos.puccampinas.edu.br/seer/index.php/reveducacao/>. Acesso em: 18 set. 2010.

PAPERT, S \& FREIRE, Paulo. O futuro da escola. Diálogo gravado e documentado entre Paulo Freire e Seymour Papert. São Paulo: TV PUC-SP, 1995. Disponível em: $<$ http://ticparaensinodeciencias.webnode.com.br/news/paulo-freire-seymourpapert/>. Acesso em: 20 Set. 2012.

MORAN. J. M, Desafios com as novas mídias. Programa de Formação continuada Mídias na Educação. Módulo Introdutório - Integração de Mídias na Educação. 2009. Disponível em <http://www.uab.furg.br//file.php/355/etapa_2/p2_11.html>. Acesso em: 23 set. 2010.

SANTA CATARINA (Estado). Secretaria de Estado da Educação. Edital no 18/2010/SED. Disponível em< http://www.sed.sc.gov.br/secretaria/documentos/doc_download/1309-edital-act-no18\%20EDITAL\%20№\%20\%20\%2018/2010/SED> Acesso em: 28 jun. 2012.

\footnotetext{
VALENTE, J. A \& ALMEIDA, F. J. de Visão Analítica da Informática na Educação no Brasil: a questão da formação do professor. Rev. Bras. de Inform. na Educação, n. 1, 1997. Disponível em < http://www.geogebra.imuff.mat.br/biblioteca/valente.html> Acesso em 28 jun. 2012.
} 